\title{
European Journal of
}

\section{Philosophy, Culture and Religious Studies}

\section{(EJPCR)}

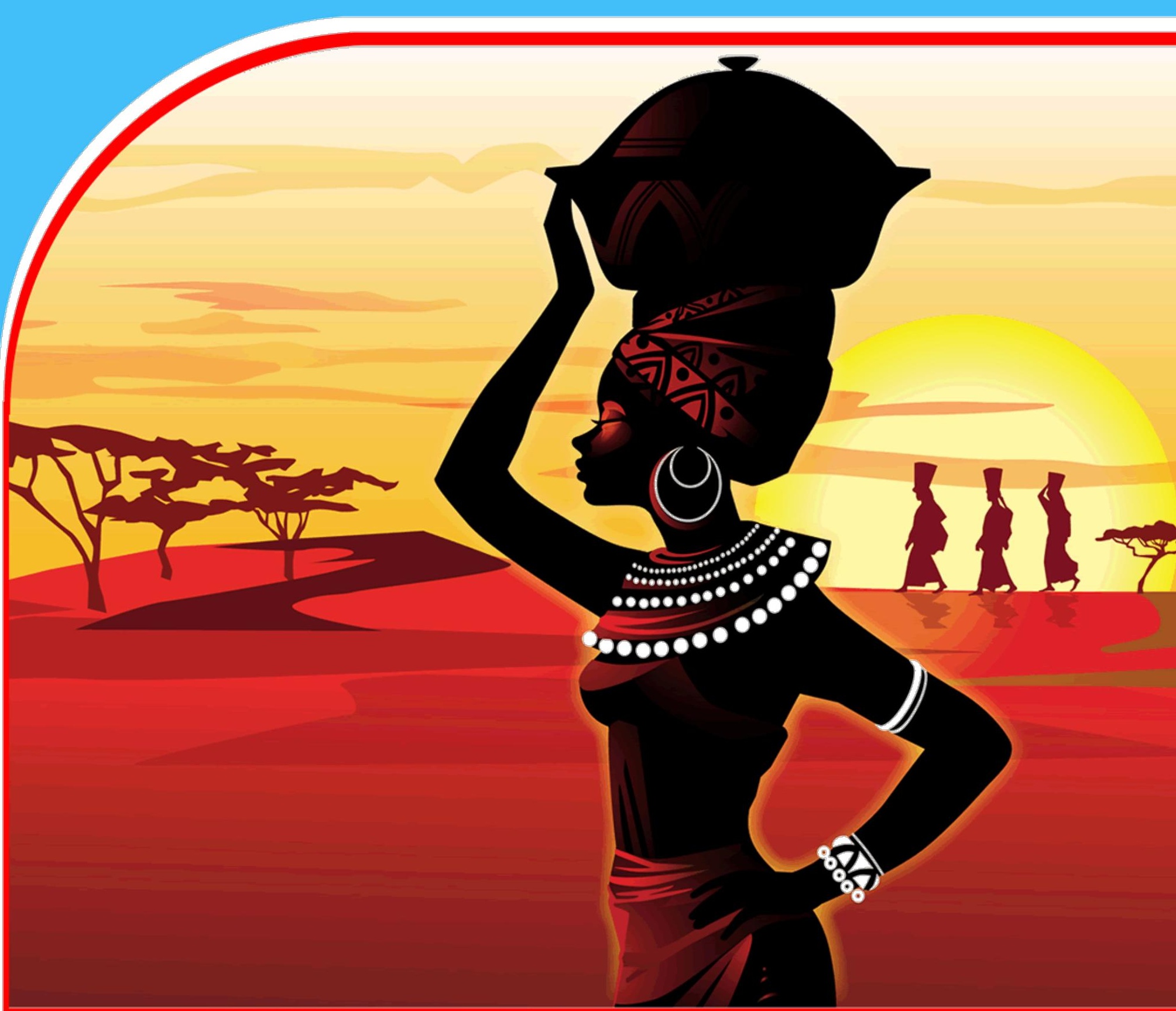

GEEZ ORAL POETRY [QENIE]: A STYLISTICAL AND THEMATIC ANALYSIS

Isaias Haileab Gebrai

AJP阐 


\title{
GEEZ ORAL POETRY [QENIE]: A STYLISTICAL AND THEMATIC ANALYSIS
}

\author{
* Isaias Haileab Gebrai, MA, \\ Ass. Lecturer, Adi Keih College of Arts and Social Sciences,Eritrea. \\ *Corresponding Author Email: isaiasrev@gmail.com
}

\begin{abstract}
Purpose: The purpose of this article is to present the stylistic and thematic analysis of Geez poetry, in a way that examines the profound and complex meaning that it carries.

Research Methodology: The article methodology consisted of qualitative research methodology and a purposive sampling was used in field work. Secondary data was also obtained from books and scholarly journals and duly acknowledged. Idiomatic and literal translation methods were used, with special emphasis on meaning rather than form. The translation from Geez to English was conducted by the researcher and content analysis was used to analyze the data.
\end{abstract}

Findings: The poems revealed a rich, valuable aesthetics and dynamic changes taking place in the cultural mold of the Geez speaking society. It has also revealed that a huge amount of Geez oral poetry still remains unrecorded. It has also shown that Geez oral poetry is not being learned by the young generation and this could lead to a loss in cultural practices embodied in it.

Unique Contribution to Theory, Policy and Practice: The article will contribute to the preservation, documentation and research endeavors being undertaken by researches, educators as well as policy makers involved in areas related to the study of the classical language of Geez. This is because none of Geez poetry has been composed, written or recorded in any parchments or books by the churches at all. Hence, it is only too obvious that a massive amount of poetic wisdom has been lost that future generations could have benefited from.

Key words: Geez, Qenie, Oral Poetry, Language, Literature 


\subsection{Introduction}

Geez is a classical language of Eritrea and Ethiopia. It is widely believed to have been spoken in the region until the fall of Axumite kingdom around the $10^{\text {th }}$ Century AD. At the moment, it remains confined only to church services in the Eritrean and Ethiopian Orthodox Tewahdo Christianity. A vast amount of literature has been written in Geez language, at the heart of which is Geez Qenie - vis-a-vi Geez Oral Poetry. Geez Oral Poetry has been composed in Eritrea and Ethiopia for hundreds of years. While Geez Poetry is oral, the rules for its composition are written and learned. The rules for the form, meter, rhyming patterns, rhythm, diction, phrases, lines, stanzas, figures of speech and so on are all fixed and written formulas. Therefore, students of Geez poetry are expected to master the rules of the composition before they are recognized and graduate as poets in the language. However, the end products, i.e. the poems themselves are simply oral and left for memorizing minds to savor. On every Sunday services and on countless of other religious or cultural festivals, Geez Poetry is composed to highlight the occasions.

There have been attempts by various researchers to save some of the oral poetry. The University of Addis Ababa is reported to have researched around important schools of Geez poetry and recorded thousands of oral Geez poems. But, most of these oral poems have not yet been published. Alemayehu Moghes, a former Geez language instructor at the University writes:

We have, with the help of 'Survey of Language Use and Language Teaching in Eastern Africa' gone in the summer of 1968 to Washera [an Orthodox Tewahdo Monastery in Etiopia] and collected 24,733 oral Geez poems. However, they haven't been published yet, owing financial shortages.... Moghes (1987, pp, 5)

As a result of it remaining oral, Geez oral poetry did not receive the attention that the rest of Geez literature, especially that of Manuscript cultures have received. Currently many researchers in Eritrea, Ethiopia, and in several European research institutes are researching and documenting vigorously the rich written literature of Geez from old times, which for the most part is in the form of parchments. However, while most of the materials that are being rescued, documented and researched are works of literature, one cannot fail but notice that the primary focus of all this research seems to be directed toward the linguistic originality of the script of Geez language rather than the literary aesthetics and Geez tradition contained in those works. This, plus the relatively late introduction of Geez Poetry teaching in Geez literature (which is arguably about two thousand years old) seems to be the reason why the profusely rich Geez oral literature in general and Geez oral Poetry (Qenie) in particular have yet to be receive significant attention in the study of Geez literature. Another reason for the lack of enthusiasm in researching the imaginative aspect of Geez is the popular notion that Geez literary materials are merely religious and that no real secular stories could be found in them. Steven Kaplan writes:

The primary concern of hagiographic texts is by definition the saintly hero. Events were likely to have been invented or suppressed in an attempt to further his reputation. Since most saints were the male leaders of monastic communities, the hagiographic texts offer comparatively little 
information on female children, the way they were seen to differ from males, or the manner in which their early lives and education differed. Indeed, even in their depiction of male children, the young seldom speak except to utter words of precocious wisdom. (Kaplan, 1997).

But the fact remains that Geez literary materials and even the church hagiographies are full of secular stories and historical documents. In those ancient materials of Geez literature, one can find a vast richness of socio-economic accounts of the times when Geez was the language of the state as well as the language of the people, especially those of the very vibrant civilizations of Axum and Adulis. Fekade Azeze writes:

Axum is world famous for its stelae which date probably from the third or fourth century A.D. It also had coins made of silver, bronze and gold minted with the engravings of the kings. The author of the Periplus reported that its Port Adulis 'was established by law' and had imports 'among others sheets of soft copper, small axes, a little wine from Italy, gold and silver plate for the king, made after the fashion of the country, military cloaks, Indian iron, steel, and cotton-cloth.' (Azeze, 1988.

There is no doubt that Geez was and still is widely considered to be the sacred language of Eritrean as well as Ethiopian Christian society. Be that as it may, the Geez literature, especially that of Geez Poetry has a huge reserve of profound and complex works of figurative language and narration that studying it is of paramount importance. The literature of Geez, especially Geez Poetry should be critically studied, not only because it reflects the popular culture but also because it may reveal a great deal of the social changes taking place in the dynamic cultural mold of the society. Theodore Huebener writes:

Geez, the sacred language, has a rich body of literature, consisting largely of religious and philosophical writings, as well as chronicles, poems, and songs. It has preserved its integrity throughout the centuries mainly because of its strong resistance to change. It has always resisted the acceptance of loan words from other languages. (Huebener, 1969).

A huge amount of grammar and poetic structure manuals were produced originally in Geez. These include teachings and techniques of Qenie (poetry) and Sewasew (grammar). Geez Qenie demonstrates lyrical poetry in a complex manner for it is composed with utmost skill and command of the language that it bemuses even speakers of the language. As a result, not all speakers of Geez can produce it. For someone to be a poet in Geez Qenie completely, they have to study the art for up to seven years and to become a poetry teacher, they need to stay in a Qenie School for up to seven years of additional time. What goes in to the making of Qenie composition is the reason it takes a high level of mastery and a great deal of time to master. Geez Qenie is divided in to more than 16 types, each of them with different forms and usage, as well as lyrical notes.

The subject matter of Geez Qenie is also diverse. Some of them are for happiness, others are for sorrow, some are practiced during fasting seasons, such as the lent season, others during happy and festive moments, some are short and highly charged with figurative words, and others are long and still full of aesthetics. Their themes are wide ranging: from family matters to higher political criticisms, from praises of God and saints to gossip and pun among 
elite church circle, from day to day socio - economic affairs to expressions of good and bad aspects of harvest, well being or poverty, justice or oppression, beauty of nature or the dangers of the wild, seas and oceans or mountains, deserts, love, hate etc.

In order to understand the composition of Geez Qenie (Poetry), one needs to know about how Geez letters, phonemes, words, word initials, pre-initials, word endings, pre endings, stress patterns, initial phrases, middle phrases, final phrases, and rhymes are constituted. Geez letters have seven variants which can be arbitrarily pronounced as: /aal, /ool, |eel, |ul, |iel, |el,

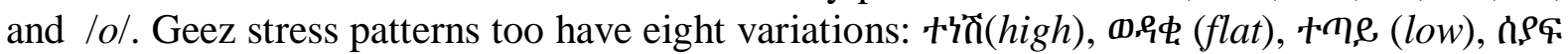

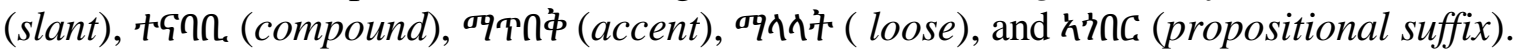

\section{Findings}

The following analysis of Geez Oral Poetry is a general overview and comment on the structural and thematic aspects of the sixteen types of Geez Poetry. All of the Geez poems that have been selected for this article are lyrical poems, which are put in to songs, which in turn have to be learned and mastered before one could actually sing them. That is when the form and the meter of the poems come handy, for if the structure is not right, the singer cannot put them in the right tone. Some of the poems included in this article have been collected from field research by the researcher and others quoted from a poetry structure manual by Alemayehu Moghes, 1987. They have been translated in to English by the researcher.

\section{Geez Gubaie Qana:}

Form: Geez Gubaie Qana is the shortest of all types of Geez poems and has the shortest phrases. It is composed of two lines and its initial line consists of 2 - 4 words, while the last line consists of between 5 and 7 words. The first stanza has its initial phrase as high and slant from 2 - 4 letters each. Its final phrase is constituted of a high and a slant from 5 - 7 letters. The final phrase can also be constituted of flat and low from 5 - 6 letters each. In a Geez Gubae Qana first stanza's final phrase, a slant morpheme is not acceptable. The second stanza is not different from the first stanza. Therefore, it follows the same pattern of phrasal construction. Example of a Geez Gubae Qana (By Anonymous)

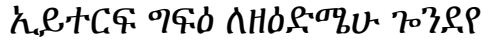

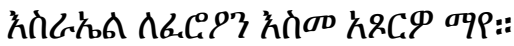

Payback is inevitable for whom it is overdue

as Israelites with water loaded the Pharaoh.

Theme: The message in this poem seems to be quite straight forward, despite its use, as simile, the Biblical story of the drowning of the Egyptian Pharaoh in the Red Sea on the account of the Israelites. But it is loaded with complex and profound meaning. The moral it conveys may be viewed as a political rebuke for people in power who have ruled for far too long, that in the end they are bound to have to answer for their heavy handedness. But there is also another implicit message for farmers in it as well, because it implies that a harvest that is not collected in time may be spoiled by late rain.

\section{Ezl Gubaie Qana}

Form: Ezl Gubaie Qana is not very different from Geez Gubae Qana in form and meter. However, it is distinct in sound and in its usage of phrases when it is put in to song. 
Otherwise, it is a two-lined lyrical poem. Ezl Gubae Qana also puts a middle phrase, making it look as if it is different from Geez Gubae Qana. The additional middle phrase is put not because of the rule but by the choice of the poet. Its initial phrase consists of high and slant from $2-7$ letters each, and low of $1-6$ letters. The succeeding four words all follow the Geez Gubae Qana formula. When a middle phrase comes in, it consists of low and slant morphemes having $4-5$ letters each, low between $3-5$ letters. The rhyming pattern is like that of Geez Gubae Qana. Example of an Ezl Gubae Qana (by Gelanesh Hadis)

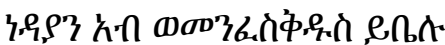

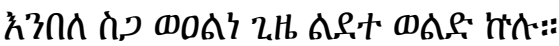

Poor Father and his Holy Spirit say, We spent without meet every Christmas day

Theme: The above poem was composed in a way that conveys double meaning. The first meaning suggests that The Holy Father and The Holy Spirit in the Christian faith were without The Son, who, according to The Bible, "took human flesh from St. Mary" when He was born, hence "Christmas Day". The second meaning suggests that a certain financially poor father is down in spirit for not being able to always afford to buy any meat to celebrate Christmas as is the custom in the Orthodox Tewahdo Christian community.

\section{Ezl Gubaie Qana with a phrase:}

Form: This type of Gubae Qana is different from Ezl Gubae Qana because it has a phrase right in the middle of the first line, otherwise, it is has similar features and sound. The following is an example of an Ezl Gubae Qana with a phrase (by anonymous)

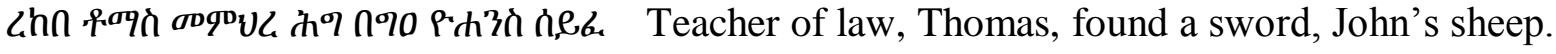

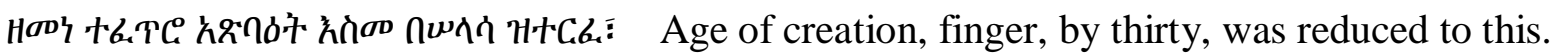

Theme: Though the poem draws its metaphor from the story of Thomas's hesitation in The Bible, the hidden message is for today's youth. As the Apostle Thomas had His fingers burnt in that anecdote when "he put them inside Jesus' wound to prove that it was indeed Him", to days' youth are lacking in faith that their life expectancy is getting cut short around thirty years of age.

\section{Mibezhu}

Form: This type of Geez poetry consists of three rhyming lines like the poem called Zeamlachie. Its only difference is in the number of its phrases and its Manderderias (middle phrases). The first and the third lines are usually longer than the second line because they contain two phrases each, while the second line contains only one phrase. In total, Meebezhu has, eight phrases in all of its three lines. Its initial phrase follows that of Geez Gbae Qana. Even the rest of the phrases can follow the pattern of either initial or final phrasing of Geez Gubae Qanna. The rhyming pattern of Mibezhu is high and slant morphemes $2-7$ each (5 is not accepted), low morpheme of $1-6$ (4 is not accepted), flat morpheme of $1-6$ (4 is not accepted). The receiver for the high, slant and low morphemes is all in all constructed of letters ranging from $4-5$. The receiver for low, all in all, consisting of 5 letters each (4 is not accepted). The phraseology of the initial and final phrase follows Geez Gubae Qana's rhyming pattern. The following is an example of a Meebezhu (by Tecle of Washera). 


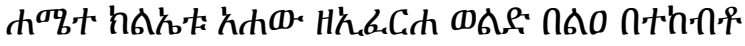

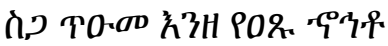

Not heeding his brother's, Son ate alone, delicious meat, by locking his door,

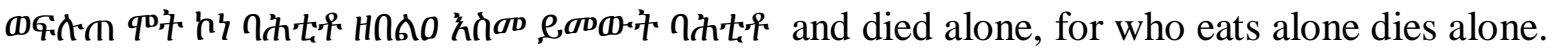

Theme: At first glance this poem seems to be about three "brothers", of whom one is criticized as having excessive selfishness and that he is isolated in death as he isolated himself in life. The details show that he had eaten meat alone and by closing his door, not wanting to share with his "brothers". The implicit message; however, is about Trinity, i.e. The Father, The Son and The Holy Spirit, from among whom, The son, is the only one, who, takes a human flesh, and "closing his door", signifies that He was born of a virgin, without any sexual intercourse.

\section{Waziema}

Form: There are three types of Waziema, but the most frequently used one is the one that has five lines, which is also called the long Waziema. The other two are known as Short and Medium Waziemas, depending on their length. This type of lyrical poem is usually composed on the eve of important days in the Orthodox Tewahdo church to commemorate different Saints or God. Its initial two lines are framed after that of the Geez Gubae Qana formula, i.e.; $4-5$ lettered high and low morphemes (flat morpheme is not accepted). The following two lines (3 and 4) don't have middle phrase, otherwise, they are also like Gubae Qana. The $5^{\text {th }}$ line has a rhyming pattern of high, low, and slant, morphemes with 6 letters each, while low morpheme of from $4-5$ letters. The following is an example of a Waziema. (By Merigieta Giedie)

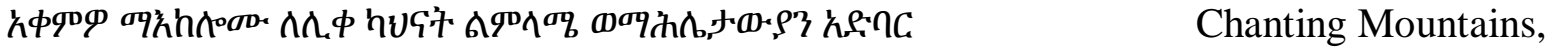

put the highpriest greenery in their midst.

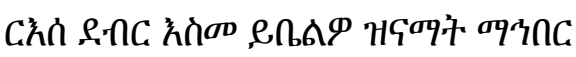

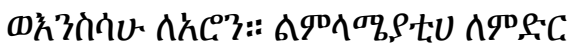

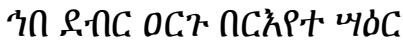

$+\lambda \omega . \hbar \pi \Lambda . \hbar \omega \cdot q C$
The league of rains called him chief of monks, and the product of the land, cattle of Aaron's, climbed mountains in search of grass, followed by escarpment goats.

Theme: This poem is written in celebration of the greenery in the rainy season. It has been portrayed as the focal point of all attention and high value. It is placed high above the mountains that the rains themselves see it as the reigning supremely in the land. So too, attracted by the greenery, the cattle and the goats ascended the mountains. This is a very colorful and pictorial celebration of nature at its best; another testimony of the fact that Geez Poetry is not merely religious composition.

\section{Selasie}

Form: This type of lyrical Geez poem is especially composed at festive events, on important days in the commemoration of saints as well as that of God by the Orthodox Church poets. It is also composed on weddings of deacons. It has six rhyming lines. The lines it consists are: an initial Selasie phrase, a supporting phrase, two Gubae Qana lines, Menderderia line, the 
fifth line (which is for the most part similar to the fourth line of a Waziema poem), and a sixth line, which is absolutely similar to the ending line of a Waziema poem. Selasie is the poem, which is learned after a student has completed Meweds Poem. Its initial phrase has one high and one slant morpheme of $2-4$ lettes, (low morpheme is not accepted), and the receiving phrase has between $4-5$ letters. The manderderia phrase is composed of 6 lettered words in which a slant morpheme is not accepted while high, flat and low are accepted. Its supporting phrase is composed of high and slant of $6-7$ letters each, low and flat $5-6$ letters each. The receivers of high and slant morphemes have 4 letters each. The receiver of low has four morphemes of $4-5$ letters each and the receivers of flat morpheme have 5 morphemes each. When a supporting line is short, it has the futures of a Gubae Qana's initial phrasal pattern. But the words in middle phrases have 5 letters each. The following line follows a Gubae Qana pattern. The fifth line consists of high, low, slant of 6 letters each, and flat has $4-5$ letters. The sixth line is absolutely similar to that of Waziema's rhyming pattern. The following is an example of Selasie poem. (By Merigheta Berhane)

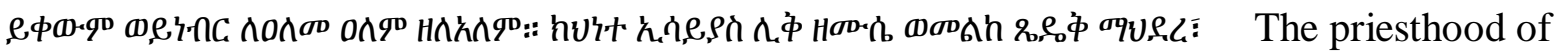

Isaias, the elite of Moses and Melke Tsedeq's home, Stands and sits forever and ever,

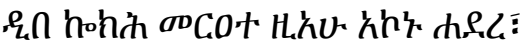

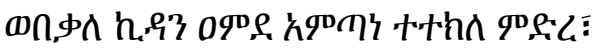

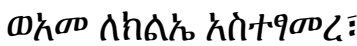

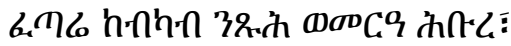

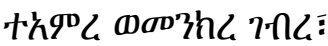

For he laid his bride's base on a rock, With a pillar of a covenant he was rooted deep,

And as he made two ways unite, The creator of weddings and marriages together, did an incredible miracle.

Theme: This poem was composed, on the researcher's own wedding by a close friend in 2009. Because the friend is a well-meaning fellow, it is mostly highly characterized by a flattering tribute. However, because he is a seasoned poet in the Geez Verse and Geez Literature, he was still able to maneuver and throw some figurative jibes in a very cheeky and abstract manner. This is demonstrated in the second line, in which the bridegroom: vis-à-vis, the researcher is said to have "his bride's base on a rock." There are two ways of looking at this detail: one is the representation in The Bible, of faith as "Rock", and the representation of church as "Bride", in which case he is simply praising the groom for laying his faith on a strong base. The second one is the fact that the bride is from the town of Adi Keih, which is one of the rockiest of places in the Southern Zone of Eritrea. So it could be argued that the composer had attempted to throw a pun at the groom and express his dismay for, against all expectations, choosing a woman from a place outside of his original region; which happens to be the same locality as the composer himself, and cleverly hinting that the groom was too stubborn to stand up to resistance from some members of his family who may not have been initially impressed with the union.

\section{Zeamlachie}

Form: This type of lyrical Geez Poetry is composed of three lines. The first line is exactly like that of Geez Gubae Qana's; except that it is not followed by a phrase. Zeamlachie is frequently used during lent season among prayers and hymns prepared for that particular 
fasting period. Its middle phrase is composed of low morpheme of $3+3$ letters. There is usually a middle phrase, called Manderderia in Zezmlachie, waziema, Selasie, Zeyezie, Sahleke, Meweds and Ettane Mogher types of Geez Poems. According to their types, they come under the names of Short, Medium and Long Manderderia. An initial Short Manderderia consists of low morpheme of $1-3$ letters. Medium Manderderia comes only as a middle phrase. Long Manderderia has slant morphemes consisting of $2-4$ letters and low morphemes of $1-3$ letters. The following is an example of a Zeamlachie poem (By anonymous).

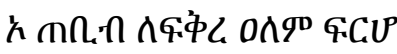

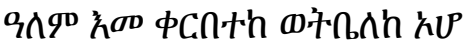

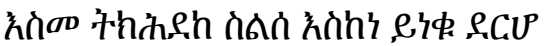

O wise man beware the world's love, When the world is close to you and says yes, Before cock-crow will deny you thrice

Theme: This poem portrays a cynical view of the world because it is basically advising the listener (Geez Qenie being oral poetry), who is considered a wise man, to heed the dangers that are present when life is good, because it could be tempting and there might be a sting in the tail later on. Everything that appears to be rosy at the start might bring difficulty somewhere down the road, and is looming so dangerously close that he won't even notice when it strikes.

8. Meweds: This type of Geez lyrical poetry is the last one that students learn to rehearse and compose. The rest types of poems can be mastered by listening to other poets composing them during church services. When a student reaches at this level, i.e., meweds, he or she is supposed to be well versed in Geez poetry. So meweds is the icing on the cake, so to say, in the Geez school of Poetry. In meweds, one can deal with worldly as well as religious matters. The rhyming pattern of Meweds has as its initial phrase and its receiver a Gubae Qana formula. Its manderderia constitutes of morphemes which have 6 letters each. In order to avoid confusion with zeyzie, however, it can be composed with 5 letters for each morpheme. The following line follows the Gubae Qana or Meebezhu's formula. The third line is as Gubae Qana, with 4 morphemes of $4-6$ letters each. The fourth line follows a Meezezhu formula. The fifth line follows the initial and final phrasal pattern of Gubae Qana formula. The sixth line follows a Meebezhu formula and the seventh takes a Gubae Qana final rhyming formula. And if the poet decides to write a longer meweds, the lines follow that of a Meebezhu formula with a Gubae Qana final phrasal patterns. That way more lines could be added. The following is an example of a meweds poem (by Alemayehu Moghes):

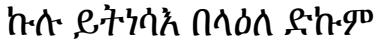

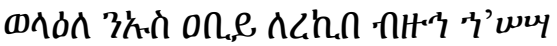

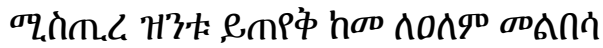

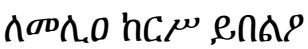

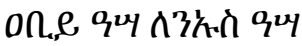

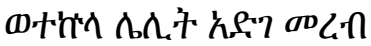

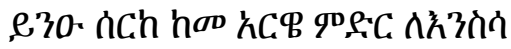

Everyone rises on the weak

and the big on the small, for extortion's sake

The secret has to be known, for it engulfs the world

To fill its stomach, the big fish eats the one the small, The wolf eats wild asses at night as a beast attacks the prey when the sun's curtain is shut 


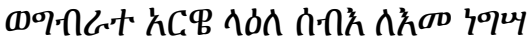

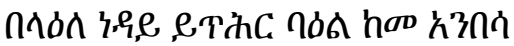

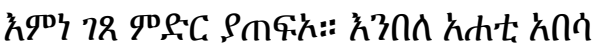

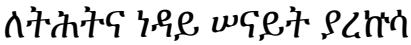

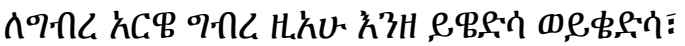

Human beings turn on each other with such act

The rich roars on the poor as a lion and makes him disappear without a reason Tarnishing the poor's humility down he pays great tribute to his of animalistic action.

Theme: The above meweds is a clear example that Geez poems are not merely about religious affairs and that they also deal with human behavior as well. It is a criticism of the human tendency to suppress the poor and the weak among us. The simile it uses is the resemblance to wild beasts. By appealing in to a deep human morality and psyche, and criticizing moral deficiencies, therefore, it aspires to alleviate injustice in the society.

\section{Geez Etanemoger:}

Form: This type of Geez poetry is composed right at the end of mass on every Sunday church service during fasting time; such as Lent and other declared fasting seasons in the Orthodox calendar. It is preceded by another poem, called Geez Kibr y'etee. It has seven lines and all except the first line rhyme together. This type of Geez poem is sung by another deacon or a clergy man, while the composer delivers the verses to him. The first four lines are called Etane Moger, while the remaining three lines are called Asere Negus or Asere Negasi. In these three lines the composer can discuss about a king or politics, about the country, about the times etc. Geez Ettane Mogher's first line has four phrases, of which the first two follow the Gubae Qana formula. The following line follows Ezl Gubae Qana long phrse. The third line follows Geez Kibr Yeetee's first line and the fourth line is a manderderia. The second part of Geez Ettan Mogher, the Asere Negus, has only three lines. The first phrase is like that of Ezl Gubae Qana and has a long middle phrase. Its rhyming phrase is like that of the initial or final line of Geez Kibr yeetee. The second line is like that of Long Gubae Qana. The third line's initial phrase, as a manderderia's initial phrase has high and slant from $2-4$ morphemes, low from $1-3$, flat is not accepted. The next phrase, just like manderderia, has high, low and flat with 6 letters each. More than 6 letters are not accepted. The rhyming line has high, low, flat and slant, each with 4 letters each. The following is an example of Etane Mogher by Tecle of Washera.

えのH,ん

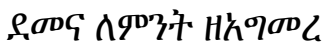

carried clouds?

久

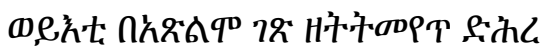

कל.

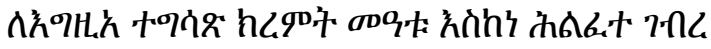

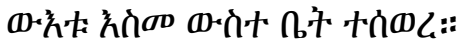

She was ordered to pour nature's water of joy And she turns back with a darkened face

As for drought, the servant of winter, knowing well the prophet's wise words Making sure that summer's wrath runs for ever, has hidden himself at home. 
Theme: The above poem is a celebration of the rainy season. It tells how much strong and threatening the rainy season could be. By giving human attributes to drought, the sky, and the different seasons, it shows us the dramatic cycle of summer season and the majestic influence it has in bringing about changes on drought and on winter.

\section{Ezl Etane Moger}

Form: Ezl Etane Moger, like Geez Etane moger, is divided in to two parts: Etane Moger and Asere Negus. Ezl Etane Moger is longer than Geez Etane Moger because it has eleven lines. The first six are called Etane Moger, while the remaining five are called Asere Negus, in which the composer is at a liberty to discuss non religious issues such as politics, economy, social affairs, etc. The first line is just like Gubae Qana, except for the phrases. The second line's initial phrase is like that of Gubae Qana an its rhyming end is high, low, flat and slant, with $4-5$ letters each. The third line's initial phrase is like Geez Kibr Yeetee's rhyming end but its rhyming end is like Gubae Qana's rhyming end. The fourth line is a supporting phrase (though some poets use that of Meebezhu's). The fifth line is like Ezl Gubae Qana. It may or may not take a phrase. It is also made of only flat morphemes of 3 letters each. The sixth line is Manderderia. The Asere Negus part has five lines. It is important that it rhymes with the Ettane Mogher part. However, depending on the poet's decision, its theme may or may not concur with that of the Ettane Mogher's. The Asere Negus's first line is like Ezl Gubae Qana with a phrase. The second line is also like Ezl Gubae Qana. It it adds a phrase, it takes flat morphemes of 3 letters each. After this, from the fourth line up to the ending line, the rule is similar to that of Selasie's. The following is an example of an Etane Mogher by Tecle of Washera.

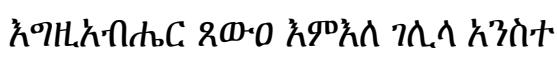

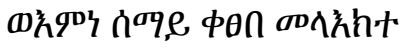

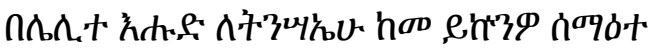

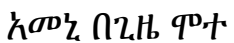

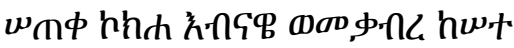

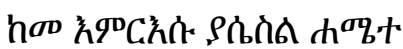

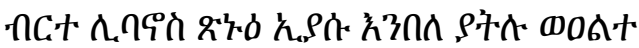

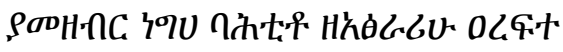

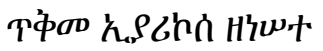

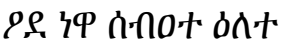

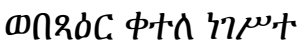

God summoned women from Galilee and angels from heaven, to witness His resurrection on Sunday night, or when He died, Annihilating the rock and opening the grave, to cleanse Himself of blame. Joshua, the iron-man of Lebanon with out leading laborers, was annihilating his enemies' backyard, and destroyed the gates of Jericho. There he toured seven days, and with valor killed kings.

Theme: The above poem starts off with Biblical reference of Jesus and the people in the story around the times He was "buried and resurrected" as well as the angels narrated in The Bible. It tells how He had to convince angels as well as human beings that He was the real God and hence consolidate His position on earth as well as in Heaven. Then it proceeds to tell about the story of Joshua, from The Old Testament and how He was able to defeat the kings alone in seven days. There are critics who interpret this to the Six Days' Arab - Israeli war. However, there is no easy indication that it is actually what the poem implies in the Asere Negus for the simple reason that the composer mentions seven days and not six days. 


\section{Long Kulkmu}

Form: This type of poetry has thirteen lines, making it the longest of the Geez poems in general. Its melody much more resembles that of Meweds, except that it is longer. This type of poem is composed during the lent and other fasting seasons in the Orthodox Tewahdo Church's calendar. Long kulukmu is composed of a nine line rhymes of Meweds plus one line of the seventh line of Meweds. The next lines follow meweds' second line or a Lealem's third line. Its eighth line also resembles zeyzie's fourth line. The first 9 lines of Long Kulukmu are similar to the 9 lines of Meweds. The only difference is that Long Kulukmu adds one more rhyming word. This additional rhyming word is added starting from the seventh line. Therefore Kulukmu is Meweds plus more rhyming lines. The eighth line of Long Kulukmu resembles that of Zeyezie's forth line. The following is an example of a Long Kulkmu by Alemayehu Moghes

ก८.

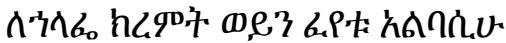

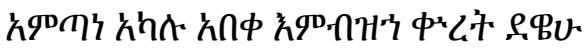

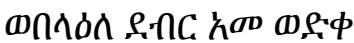

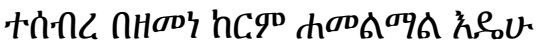

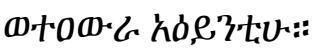

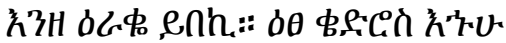

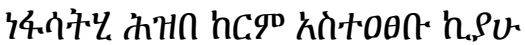

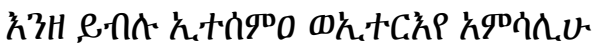

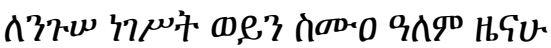

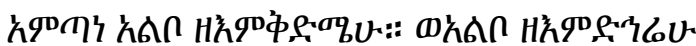

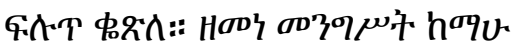

え
Rain and hail, pear's enemies

Robbed, the clothes off grape, passenger of summer

As his body had been tormented from winter's cold

And when he fell on the mountain,

his green hand was broken in the summer season

his eyes also were blinded

while tree, his brother was crying and nude, and winds, people of summer, by him astonished They said, this is unheard of or unseen of the king of kings, grape, who has world renown as there was no one before him, or after him,

And the famous leaf of regime's time, for there was no one before him, nor one after him.

Theme: The above poem is a demonstration of the power of the rainy season, especially one accompanied with strong torrents of wind and hail. It describes how hail and rain destroy the trees on a mountain. What makes the strength overwhelming is the fact that even grape, which is revered by human beings as being a highly valued plant also gets the wrath of summer, in a way suggesting the blood of Jesus. But most importantly, the poem is a metaphorical account of the Ethiopian Revolution of 1966 that removed Emperor Haile Selasie of Ethiopia from power. It presents the term of power for any government, for that matter, in a pitiful manner, as its end in a violent way is not very kind and as flowery as when the person was in power.

\section{Hatsir Kulkmu}

Form: This type of Geez poetry has two lines. The first line is written in the style of any Gubae Qana type of poem. If it had the second line first, it would exactly be another type of 
Geez poem, called Short Waziema. The following is an example of a Hatsir Kulkmu by Alemayehu Moghes

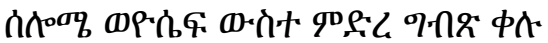

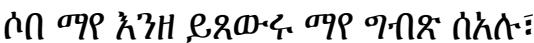

Salomé and Joseph were despised in Egypt,

For, while they were carrying water, they

begged for Egypt's water.

Theme: On the surface of it, this poem laments the suffering of Salomé and Joseph in the land of Egypt. It narrates how they were thirsty, while they were in possession of great importance to the world, according to The Old Testament. However, the message of the poem had a deeper meaning to anyone in general, who has been denied and made to beg for something that he or she rightfully deserved.

\section{Geez kibr Yeetee:}

Form: This type of poetry has four lines, the second and third of which are written in exactly the same rule as the first and second lines of Gubae Qana type of Geez poetry. Geez Kibr $Y^{\prime}$ 'eeti is composed during fasting times and is sung by the composer himself, followed by $E z l$ Etane Mogher, which he leads another singer to put the verses in to a measured song. The second and the third lines of Geez Kibr Yeetee are pure Gubae Qana lines. The first and the fourth lines are also the same and resemble that of Meebezhoo's. They are only different from Meebezhoo's in that Meebezhoo's morphemes have high an slant from $4-5$ letters, while Geez Kibr Yeette's have 4 letters each. Geez. Kibr Yeetee's first and final lines' base and receiver's initial lines take a Gubae Qana's formula. The rhyming pattern is high and slant from $2-7$ (5 is not accepted). If it is low, it goes from 1-6 letters (4 is not accepted). The receivers of high and slant take 4 letters each, low's receiver takes high, low, slant and flat, each from $4-5$ letters. And the receiver of flat takes high, low, flat and slant, with 5 letters each. The following is an example of Geez Kibr Yeetee by anonymous.

ov6.

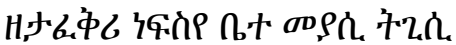

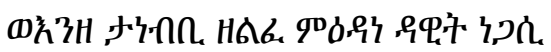

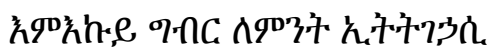

Drink, while it soothes the soul, why doesn't it serve as food? And my soul that loves ale, While always reading the wise advice of King David, Why don't you stay away from evil deed?

Theme: This poem is a rebuke to drunkards and alcoholics because, on top of being regular drunks, they are being depicted here as doing bad deeds, driven by liquor. It gives drink its due: the fact that drink does, indeed sooth the spirit of people, but, consumed in excess, has the negative effect of leading its drinkers astray. Even though it contains some mention of religious context from The Book of Psalm, it qualifies well enough for being a totally secular and social poetry in its content.

\section{Ezl Kibr Yeetee}

Form: This type of poetry has four lines, in which the first and the last lines are written by the formula of Ezl Guba'e Qana, with a Phrase type of Geez poem, while the second and the third lines are written in the same formula as a Guba'e Qana that doesn't have a phrase. Ezl Kibr Yeeti is composed on Sundays and during important holidays in commemoration of life of saints in the Orthodox Church's calendar. Since the song is considered a merry song, it is 
practiced on days other than fasting times. It is sung by the composer himself. The following is an example of Ezl Kibr Yeetee by Alemayehu Moghes.

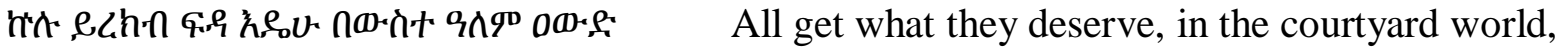
久⿵D, hov $\Lambda$ h 久

Theme: This poem depicts the world as a "courtyard", where everyone would ultimately be judged according to their deeds. The prosecutor, according to this poem is the innocent and patient people that he or she might have been hurting or marginalizing in a tribal or racist treatment. By condemning their "patient" God, in the Crucifixion Day, the poem says, human beings brought about their own death. The implication here is that when human beings break loose from God's rule, they are the ones that pay the price.

14. Sahleke -This type of Geez poem is composed of four lines. The first two lines of Zey'zie type of Geez poem are also called Sahleke because they are written in exactly the same formula as the first two lines of Sahleke. It is composed on historical moments, which call for people to seek guidance from above, explaining the name "sahleke", meaning "Thy mercy". The following is an example of a Sahleke by Alemayehu moghes.

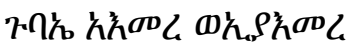

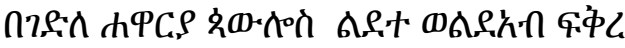

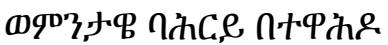

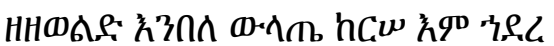

Conference knew and never knew In the Gospel of Paul, birth of Son of God, Love

Theme: The above poem was composed on the occasion of the Oriental Church ArchBishopal Conference that Addis Ababa hosted in 1982. It sums up the spirit of the conference, which mainly focused on the different beliefs that existed concerning the birth of Christ. The poem says that the conference was wise in some of the points and missed on other points and that there was some division about the matter among the representatives.

\section{Zey'ezie}

Form: This type of Geez lyrical poem has five lines. Sometimes it becomes six lines by repeating the fourth line once again as it is put in a song. It can be composed at any time of the year. However, as its name ("of now"), implies, it is best used to express the situation in the context it is composed in, i.e. the situation in the country, in the community, in church, etc. While Zeyezie's first line's initial phrase has a Gubae Qana formula, the following phrae has morphemes of 5 letters each, with 6 also acceptable and starts with Waziema's initial phrase. The next one is almost completely Gubae Qana, except that it doesn't have a phrase. On top of the second line, a supporting phrase, which has the traits of initial phrases of a Waziema's, can be added (depending on the poet's wishes). The next phrase is a supporting one. The third line has an initial phrase like that of a Gubae Qana and a final phrase like that of a Meebezhu's. The fourth line's initial phrase is exactly like that of a Gubae Qana, while its final phrase has morphemes of 6 letters each ( 5 is also acceptable). The fifth line, from the beginning to the end has a Gubae Qana formula and doesn't have a middle phrase. The sixth 
line is a repetition of the fourth line. The following is an example of a Zey'zie by Alemayehu Moghes.

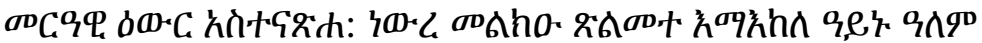

Bridegroom, the blind, cleansed the blame of his dark deeds, amid the world, his eye, えกัव As Abiye Egzi'e gave

him a magazine of Debre Medhanit so he an see Adam,

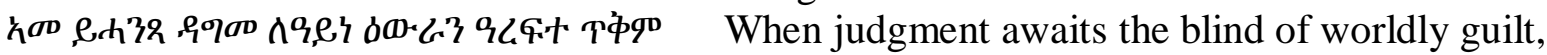

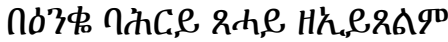
With sun, the bead that doesn't go dark,

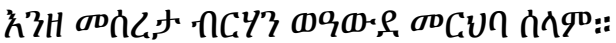
For its base is light and peace its courtyard.

Theme: The above poem deals with how a bride groom goes to the church of Debre Medhanit and is confronted face to face with his sin because the abbot of the church explains to him what his sins were. The groom is symbolized as "blind" because he didn't have a clue about the sins that he inherited from Adam, before he came to the church. Such would be the case for people who are unaware of their guilt as they die according to the poem, as clarified to the groom in the "sunny" way of preaching so that he was able to be satisfied and find peace afterwards.

\section{Conclusion and Recommendation}

One of the great examples of oral Geez tradition is Geez poetry. This rich and quite complex cultural heritage is only mastered by very few speakers of the language, who study the art for up to seven years. Their usage of figurative speech is so high that so much history and analysis of the past is to be extracted by studying them. However, the oral poems remain intangible as intangible can be because they are not recorded in any books or manuscripts by the churches where they are composed. Even though there are still speakers of Geez, who specialize in the art of oral lyrical poetry and remember many oral poems from notable poets of ancient times, not much is recorded or published in written form. Therefore, there is a great probability that the tradition will be forgotten and much needed history and lessons from the past will disappear in obscurity. The trend is particularly worrying because Geez oral poetry is not as vibrant as it used to be and the monasteries in Eritrea and Ethiopia are not producing as many poets as they used to in the old times. Throughout its history, Geez poetry has not been meant to be recorded or written down in any form of books or parchments, but to be rehearsed and for the moment. No serious attempts have been made by the monasteries or churches, which are usually custodians of the tradition to record it in writing. Therefore, there is a great need for researching, recording and preserving the rich history and culture whiles the art and the knowledge of the language is still in the memory of the shrinking number of its custodians. As the oral tradition of Geez poetry is becoming increasingly endangered because students are not learning the language and the art as they used to do in the past, the continuity of oral Geez poetry is in a worrying situation. Hence concerted efforts and steps must be taken to record and study it as a cultural heritage. Oral Geez poets in churches and monasteries need to be encouraged to develop a practice of recording the composed poems in written or electronic forms.

\section{Reference:}

Azeze Fekade, The Intellectual in the Ethiopian Novel, 1930 - 1974. 1988 
Huebener Theodore, Ethiopia: The Land of Hudred Toungues, The Modern Language Journal, Vol. 53. No. 2. Feb, 1969

Kaplan Steven, Seen but not Heard: Children in Medieval Ethiopian Hagiographies, International Journal of African Historical Studies, Vol. 30, No. 3 (1997)

Moghes Alemayehu, Yeg'ez Qenie Ziema, 1987. 